\title{
Case studies in a flipped classroom: An approach to support nursing learning in pharmacology and pathophysiology. - Études de cas dans une classe inversée : une approche pour appuyer l'apprentissage de la pharmacologie et de la physiopathologie en sciences infırmières.
}

Jane Mackie

Trent University, jmackie@trentu.ca

Follow this and additional works at: https://qane-afi.casn.ca/journal

Part of the Nursing Commons

\section{Recommended Citation}

Mackie, Jane (2018) "Case studies in a flipped classroom: An approach to support nursing learning in pharmacology and pathophysiology. - Études de cas dans une classe inversée : une approche pour appuyer l'apprentissage de la pharmacologie et de la physiopathologie en sciences infirmières.," Quality Advancement in Nursing Education Avancées en formation infirmière: Vol. 4: Iss. 2, Article 6.

DOI: https://doi.org/10.17483/2368-6669.1139

This Article is brought to you for free and open access by Quality Advancement in Nursing Education - Avancées en formation infirmière. It has been accepted for inclusion in Quality Advancement in Nursing Education - Avancées en formation infirmière by an authorized editor of Quality Advancement in Nursing Education - Avancées en formation infirmière. 
Case studies in a flipped classroom: An approach to support nursing learning in pharmacology and pathophysiology. - Études de cas dans une classe inversée : une approche pour appuyer l'apprentissage de la pharmacologie et de la physiopathologie en sciences infirmières.

\section{Cover Page Footnote}

Acknowledgements: Thank you to Dr. Amy Halloran for statistical analysis and editorial support and to Ellen Olsen-Lynch for library research support. Remerciements : nous remercions la Dre Amy Halloran pour l'analyse statistique et le soutien éditorial, et à Ellen Olsen-Lynch pour son soutien dans la recherche bibliographique. 
A thorough understanding of pharmacology is crucial for nurses to ensure the safety and well-being of patients, especially as the scope of practice for nurses in many Canadian jurisdictions expands to include prescribing. Learning the complex concepts present in pharmacology can be challenging for nursing students; there is a large volume of factual information that builds upon a thorough understanding of pathophysiology, along with anatomy and physiology. Nurse educators must use teaching and learning strategies that not only encourage students' understanding of pharmacology concepts but that also move students from Bloom's early domain of knowledge acquisition into the later domains of knowledge application and analysis (Benner, Sutphen, Leonard, \& Day, 2010). Case study discussions are one active learning strategy that is used in the "flipped classroom" to encourage this synthesis of connections (Kantar \& Massouh, 2015; O'Brocta \& Swigart, 2013). The instant feedback by instructors to nursing students that occurs during case study discussions also promotes development of critical reasoning (Chan, 2013; Kalaian \& Kasim, 2017), which is a crucial part of nursing practice for the BScN prepared nurse (Benner et al., 2010; Chan, 2013). Case studies are often used in the flipped classroom in nursing education (Bristol, 2014), but there is a lack of literature regarding the assessment of case studies as a learning strategy. The aim of this study was to determine nursing student perceptions about their learning when case studies are used as a learning strategy to study pharmacology and pathophysiology.

\section{Background}

Nurses dedicate approximately $40 \%$ of their time to administering medications (Armitage \& Knapman, 2003); the complex role of medication management requires competent knowledge of pharmacology to maintain patient safety (Leufer \& Cleary-Holdforth, 2013). As the registered nurse $(\mathrm{RN})$ scope of practice in some provinces expands to include prescribing medications, effective nursing education in pharmacology is essential to reduce medication errors. Education in pharmacology often simply highlights the indication, dose, and adverse effects of a drug (Boggs, Brown-Molnar, \& DeLapp, 1988; Morrison-Griffiths, Snowden, \& Pirmohamed, 2002). However, the complexity of current health care includes multiple medications for multiple diseases, so a thorough comprehension of the actions (pharmacodynamics) of a drug, as well as potential interactions between medications, will enhance patient safety (Ndosi \& Newell, 2008). Knowledge deficits in pharmacology have been found to increase medication errors (Boggs et al., 1988; Brady, Malone, \& Fleming, 2009; Meechan, Mason, \& Catling, 2011; Ndosi \& Newell, 2008). Nurse educators need to employ effective teaching and learning strategies to move students beyond simple acquisition of knowledge to application of knowledge in pharmacology to ensure patient safety with respect to medication.

Flipping the classroom is a pedagogical approach defined as "that which is traditionally done in class is now done at home, and that which is traditionally done as homework is now completed in class" (Bergmann \& Sams, 2012, p. 13). In a flipped classroom, traditional lecture time is spent on active learning strategies like case studies, games, or practice questions to allow instructors to guide students as they work (Bergmann \& Sams, 2012). The flipped classroom is used by undergraduate nurse educators in courses such as nursing theory (Missildine, Fountain, Summers, \& Gosselin, 2013; Peisachovich, Murtha, Phillips, \& Messinger, 2016; Schlairet, Green, \& Benton, 2014), statistics (Schwartz, 2014), and pharmacology (Geist, Larimore, Rawiszer, \& Sager, 2015; Hanson, 2016). Evidence indicates that performance on midterm tests is enhanced with the flipped classroom but not on final exams (Geist et al., 2015). Nursing students indicated a preference for traditional lectures over the use of a flipped classroom 
(Hanson, 2016; Missildine et al., 2013) even when they believe that that the approach increases their understanding of pharmacology (Hanson, 2016). This preference for lectures over the flipped classroom is common and may be due to a perception of increased workload or groupbased activities (Horn, 2013; Tune, Sturek, \& Basile, 2013) as well as insecurity around being prepared for exams (Benner et al., 2010). Reviews on the evidence for use of the flipped classroom in nursing indicate enthusiasm for this approach by nurse educators. However, there is a lack of consistent evidence with respect to the best practices in the implementation and assessment of this strategy within nursing education (Betihavas, Bridgman, Kornhaber, \& Cross, 2016; Njie-Carr et al., 2017).

Nurse educators should provide situated or contextualized learning for nursing students (Benner et al., 2010). Situated learning can enhance the development of critical reasoning, which helps students determine the priority nursing concerns for patient care from a long list of issues; this supports the development of Benner's problem-based nurse (Benner et al., 2010). Problembased learning (PBL) is a foundational approach to the flipped classroom that can provide situational learning (Benner et al., 2010; Bergmann \& Sams, 2012). PBL uses carefully designed problems or scenarios to develop knowledge and understanding of specific learning objectives (Wood, 2003). PBL is done in groups with a tutor facilitating discussion (Wood, 2003). PBL has been used in nursing education in content areas ranging from pharmacology (Alton, S. 2016), to mental health nursing (Atherton, H., 2015; Balzer et al., 2016) to critical care nursing (Gholami et al., 2016). Students perceive PBL as engaging and useful for their learning (Al-Kloub, Salameh, \& Froelicher, 2014; Forsgren, Christensen, \& Hedemalm, 2014). PBL provides effective knowledge acquisition (Arrue, Ruiz de Alegría, Zarandona, \& Hoyos Cillero, 2017; Martyn, Terwijn, Kek, \& Huijser, 2014) and development of critical thinking in nursing students (Bailey, 2017; Bertacchini de Oliveira, Rueda Díaz, da Costa Carbogim, Baldacin Rodrigues, \& de Araújo Püschel, 2016; Carvalho et al., 2017; Chan, 2013; Kong, Qin, Zhou, Mou, \& Gao, 2014) as well as improving meta-cognitive ability (Lee, Nam, \& Kim, 2017).

Completely flipping the classroom for courses that contain a heavy load of factual information, such as pharmacology and pathophysiology, may not be effective due to information overload (Sams \& Bergmann, 2013). Alternating between lectures and PBL strategies may be a superior option with health science courses (Alexandre \& Wright, 2013; Mrunalini, \& Chandekar, 2015). PBL includes a variety of active learning strategies. Active learning has been defined as "any instructional method that engages students in the learning process" (Prince, 2004, p. 224). In nursing education, PBL activities range from artistic activities such as composing songs, writing poems, or drawing (Chan, 2014) to more classroom-based approaches such as simulation (Christiansen, Buus Bøje, \& Frederiksen, 2015) or case studies (Forsgren et al., 2014). Case studies are scenarios that are carefully constructed with specific learning goals in mind (Wood, 2003). Case studies are particularly useful in nursing education as they to help students in "(a) recognizing the particulars of a clinical situation, (b) making sense of patient data and informing decisions, and (c) reflection" (Kantar \& Massouh, 2015, p. 8). Case studies are designed for use in small groups with a tutor. The active interactions provided with small group learning provide superior learning to traditional lectures (Kalaian \& Kasim, 2017). Small group learning also enhances the development of students as independent learners and critical thinkers (Chiang, Leung, Chui, Leung, \& Mak, 2013).

A need for ongoing evaluation of learning strategies has been identified in order to determine best practices in nursing education (Betihavas et al., 2016; Breytenbach, ten Ham- 
Baloyi, \& Jordan, 2017; Njie-Carr et al., 2017). This study provides an assessment of case studies as a learning model through an investigation of nursing student perceptions around the use of case studies as a learning model in pharmacology and pathophysiology courses. The specific research questions are as follows:

1) What are the perceptions of nursing students about the impact of case studies on their acquisition and application of knowledge in pharmacology and pathophysiology?

2) What are the perceptions of nursing students about case studies as a learning model in pharmacology and pathophysiology?

\section{Methods}

\section{Study Participants}

A convenience sample of students from three courses was used for this study: Pathophysiology (PATHO), which is a required course for nursing students in second year; Pharmacology (PHARM), which is a required course for nursing students in third year; and Advanced Pathophysiology/Pharmacology (APP), which is a third-year elective course (after completion of the other two courses). Participation in the study was voluntary and anonymous. Consent was obtained from all participants. Demographic data were collected. Data were collected between September 2014 and April 2016. This study was approved by the University Research Ethics Board.

\section{Case Study Model}

The case study model is the same for all three courses and was designed by the investigator, who teaches both courses. The case study model used here involves small groups (typically 10-12 students). Students take turns as the facilitators of the discussion. Students meet in seminar to discuss one case for an hour. The goal for the group is to review the medication (PHARM) or illness (PATHO) that is the focus of the case study. The group will then determine the top three nursing concerns for the patient and design appropriate nursing interventions. The role of the instructor is to provide immediate feedback that is specific to the ongoing discussion. Case studies were all written by the instructor with the following guiding principles. As an active learning strategy, both knowledge acquisition and the development of clinical reasoning were the objectives. Each case study was brief (approximately 250 words) and included key patient data. The case studies included information that could be analyzed to provide the priority issues for this individual patient in this particular situation. For PHARM, the cases were about one medication; student leaders facilitated a review of the basic pharmacodynamics issues for the drug (mechanism of action, therapeutic benefit, adverse effects, and potential drug/food/herbal interactions) along with important pharmacokinetic issues. For PATHO, the cases were about one illness; student leaders facilitated a review of the basic issues for this illness (etiology, signs and symptoms, diagnostic tests, general pathophysiology, and complications/prognosis). At the conclusion of the review, the group worked together to decide the key nursing concerns and appropriate nursing interventions for this patient. For APP, the seminar groups are slightly larger (15-18 students) and the discussion is for two hours; content here is about the pharmacology and pathophysiology issues associated with acute care patients, such as patients who have experienced burns or an ischemic episode. The PHARM and PATHO course each also have a two-hour lecture, but APP does not. 


\section{Study Design}

For each course, a survey with two parts was created. Nursing students completed the survey online. The surveys used in this study were developed by the researcher. The surveys for each course were similar, but the items were tailored to the specific content of each course. The complete survey items are presented in Tables 2, 3, and 4.

Items were created in the first part of the survey to determine student perceptions of the impact of case studies on acquisition and application of knowledge. These items were created with language that demonstrates perceived capability, which connects to self-efficacy (Bandura, 2006). The second set of items was created to determine student perceptions about the case study model used as a learning strategy in this course. The items in this section were similar to items used in course evaluations; course evaluation provides an opportunity for research and dissemination of knowledge around education strategies. Statements began with "Participation in seminars made me more confident to..." to indicate the evaluation of the model; these were content specific for each course but created based on the same principle to connect the learning model with their own development. The remaining items were identical across both surveys. The Likert Scale used to measure responses was defined as $1=$ Strongly disagree, $2=$ Disagree, $3=$ Neither agree or disagree, $4=$ Agree, and $5=$ Strongly agree .

\section{Statistical Analysis of Survey Data}

The mean response (+/- standard deviation) to each item in the survey was determined. Analysis was then done to determine differences in mean responses within the two sections of the survey in each course. Responses to the items in each course were analyzed using an ANOVA to detect similar response levels. If differences were detected, post-hoc analysis was done using the Tukey-Kramer Procedure $(\alpha<0.5)$ to determine which mean responses were significantly different between items within the same course. The response to an item was considered different from other responses only if the mean response to that item was different from all or all but one other response in the corresponding section of the survey.

\section{Factor Analysis}

Factor analysis of Likert data to look for underlying concepts or themes is a common practice in education research to support tool development (Sullivan \& Artino, 2013). Data from both sections of the survey for PHARM were combined and submitted to exploratory factor analysis (EFA) and orthogonal Varimax rotation using XLSTAT. Orthogonal rotation was selected over obligate as it is simpler to interpret (Yong \& Pearce, 2013) and results of both tests are typically similar (Kellar \& Kelvin, 2012). The Kaiser-Meyer-Olkin (KMO) Measure of Sampling Adequacy was used to confirm that the data were suitable for EFA, and a KMO value of greater than 0.75 was the cut-off point to indicate suitability. An eigenvalue of $\geq 1.0$ was used as a cut-off value to determine the number of factors. The number of factors was confirmed using the scree plot. The Cronbach's alpha score for each factor was used to determine the reliability of the tool. Factor analysis was completed for PATHO and APP in a similar manner.

\section{Results}

\section{Demographic Data}

The number of participants in the study was 384, divided as follows: PHARM, $\mathrm{n}=141$; PATHO, $n=173$; and APP, $n=70$. The gender distribution of nursing students was similar across 
all three courses, with female students comprising 89-92\% of the study population and male students comprising $8-11 \%$ of the population (Table 1). This is consistent with the distribution in the typical student population in these courses.

Table 1

Demographic data

\begin{tabular}{lcc}
\hline \multicolumn{1}{c}{ Course } & Female & Male \\
\hline Pathophysiology & 159 & 14 \\
$(\mathrm{n}=173)$ & $(92 \%)$ & $(8 \%)$ \\
Pharmacology & 126 & 15 \\
$(\mathrm{n}=141)$ & $(89 \%)$ & $(11 \%)$ \\
Advanced Pathophysiology/Pharmacology & 64 & 6 \\
$(\mathrm{n}=70)$ & $(91 \%)$ & $(9 \%)$ \\
\hline
\end{tabular}

\section{Survey for Knowledge Acquisition and Application}

The average responses to the ten items from the survey in PHARM that referred to knowledge acquisition and application in pharmacology ranged from 3.7 to 4.1 (Table 2, items 1-10). The statement "I feel confident in my ability to prioritize the drug/herbal/food interactions associated with a medication in an individual patient" had an average response of 3.7; this value was significantly lower than all other responses to the pharmacology content statements.

Table 2

Mean survey responses plus factor analysis results for PHARM course

\begin{tabular}{|c|c|c|}
\hline Survey questions & $\begin{array}{l}\text { Mean } \\
\text { Response }^{\mathrm{a}} \\
+/- \text { sd }\end{array}$ & $\mathbf{F 1}^{\mathrm{b}}$ \\
\hline $\begin{array}{l}\text { 1. I feel confident in my ability to read a case study and select } \\
\text { the key patient factors that may impact safe and effective use } \\
\text { of medications. }\end{array}$ & $\begin{array}{l}4.1 \\
+/-0.7\end{array}$ & 0.742 \\
\hline $\begin{array}{l}\text { 2. I feel confident in my ability to understand the mechanism } \\
\text { of action of a medication based on its class. }\end{array}$ & $\begin{array}{l}4.1 \\
+/-0.6\end{array}$ & 0.710 \\
\hline $\begin{array}{l}\text { 3. I feel confident in my ability to link the therapeutic benefit } \\
\text { of a medication to its mechanism of action. }\end{array}$ & $\begin{array}{l}4.1 \\
+/-0.6\end{array}$ & 0.606 \\
\hline $\begin{array}{l}\text { 4. I feel confident in my ability to prioritize the expected } \\
\text { adverse effects associated with a medication in an individual } \\
\text { patient. }\end{array}$ & $\begin{array}{l}4 \\
+/-0.7\end{array}$ & 0.651 \\
\hline
\end{tabular}


5. I feel confident in my ability to prioritize the potential drug/herbal/food interactions associated with a medication in an individual patient.

6. I feel confident in my ability to detect a contraindication 4 that should prevent the use of a medication in an individual $\quad+/-0.6$ patient.

7. I feel confident in my ability to analyze any impacts on medication use associated with illness in an individual patient.

8. I feel confident in my ability to apply the general facts

$3.7^{¥}$

0.610

$+/-0.8$ about a drug safely and effectively to an individual patient.

4.1

9. I feel more prepared for clinical as a result of participating in the case discussions in tutorial.

$+/-0.5$

4.1

$+/-0.8$

10. I feel more prepared to act as an advocate on behalf of my patient to ensure the safe and effective use of medications.

4

$+/-0.7$

+/- 0.6

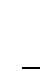
11. Participation in seminars made me more confident in
4.3
0.791 analyzing the factors about a patient that may impact the effective use of a medication.
$+/-0.8$
12. Participation in seminars made me more confident to
4.2
0.668
prioritize the safety issues when using a medication in an
$+/-0.8$
individual patient.
13. I found the seminars assisted my learning more effectively than lectures.
3.8
0.508
14. The cases were relevant and interesting.
+/- 0.9
0.526
$+1-0.6$
15. I would recommend the case-based seminar discussions as
4.4 a tool for other courses.
+/- 0.7
16. I was nervous at the beginning of the term but became more confident to participate as the term progressed.
4.1

${ }^{\text {a }}$ Likert scale, $1=$ strongly disagree, $2=$ disagree, $3=$ neither agree or disagree, $4=$ agree, $5=$ strongly agree

${ }^{\mathrm{b}}$ Correlations between variables and factors after Varimax rotation

$¥$ Significantly different from all statements in the corresponding section

The average responses to the nine items from the survey in PATHO that referred to knowledge acquisition and application in pathophysiology ranged from 3.4 to 4.2 (Table 3, items 1-9). The statement "I feel confident in my ability to prioritize the diagnostic tests required for confirmation of an illness/disease state in an individual patient" had a response value of 3.4. The statement "I feel confident in my ability to discuss the prognosis of an illness with an individual patient" has a response value of 3.5. Both of these statements were significantly lower than all statements in the corresponding section except each other. The statement "I feel confident in my 
ability to understand the etiology for an illness or disease-state present in an individual patient" has a response value of 3.8; this statement was significantly different from all statements except statement 9.

Table 3

Mean survey responses plus factor analysis results for PATHO course

\begin{tabular}{|c|c|c|c|}
\hline Survey Questions & $\begin{array}{l}\text { Mean } \\
+/ \text {-sd }\end{array}$ & $\mathbf{F 1}^{\mathrm{b}}$ & $\mathbf{F}^{\mathbf{b}}$ \\
\hline $\begin{array}{l}\text { 1. I feel confident in my ability to read a case study and select } \\
\text { the key patient factors that may impact health and well-being. }\end{array}$ & $\begin{array}{l}4.2 \\
+/-0.6\end{array}$ & 0.607 & \\
\hline $\begin{array}{l}\text { 2. I feel confident in my ability to understand the risk factors } \\
\text { present for an illness or disease state in an individual patient. }\end{array}$ & $\begin{array}{l}4.1 \\
+/-0.6\end{array}$ & 0.596 & \\
\hline $\begin{array}{l}\text { 3. I feel confident in my ability to understand the etiology for } \\
\text { an illness or disease-state present in an individual patient. }\end{array}$ & $\begin{array}{l}3.8^{\S} \\
+/-0.8\end{array}$ & 0.772 & \\
\hline $\begin{array}{l}\text { 4. I feel confident in my ability to understand the signs and } \\
\text { symptoms present for an illness or disease state in an individual } \\
\text { patient. }\end{array}$ & $\begin{array}{l}4.1 \\
+/-0.7\end{array}$ & 0.744 & \\
\hline $\begin{array}{l}\text { 5. I feel confident in my ability to prioritize the diagnostic tests } \\
\text { required for confirmation of an illness/disease state in an } \\
\text { individual patient. }\end{array}$ & $\begin{array}{l}3.4^{\S} \\
+/-0.9\end{array}$ & 0.614 & \\
\hline $\begin{array}{l}\text { 6. I feel confident in my ability to discuss the prognosis of an } \\
\text { illness with an individual patient. }\end{array}$ & $\begin{array}{l}3.5^{\S} \\
+/-0.9\end{array}$ & 0.497 & \\
\hline $\begin{array}{l}\text { 7. I feel confident in my ability to apply the general facts about } \\
\text { an illness for the benefit of an individual patient. }\end{array}$ & $\begin{array}{l}4.1 \\
+/-0.6\end{array}$ & 0.633 & \\
\hline $\begin{array}{l}\text { 8. I feel more prepared for clinical as a result of participating in } \\
\text { the case discussions in tutorial. }\end{array}$ & $\begin{array}{l}4.1 \\
+/-0.8\end{array}$ & 0.579 & \\
\hline $\begin{array}{l}\text { 9. I feel more prepared to act as an advocate on behalf of my } \\
\text { patient to ensure the most positive state of health possible in the } \\
\text { presence of an illness/disease state. }\end{array}$ & $\begin{array}{l}4 \\
+/-0.8\end{array}$ & 0.593 & \\
\hline
\end{tabular}

10. The case studies were interesting and relevant.

4.3

0.521

$+/-0.7$

11. Participation in seminars made me more confident in

4.4

0.750

analyzing the key risk factors and diagnostic tools for an

$+/-0.8$ illness.

12. Participation in seminars made me more confident in

4.3

0.817 analyzing the factors about a patient that may impact the prognosis for their illness.

$+/-0.7$ 
13. Participation in seminars made me more confident to prioritize the patient teaching issues around an illness in an

4.1

$+/-0.9$

individual patient.

14. I found the seminars assisted my learning more effectively than lectures.

15. I found the seminars assisted my learning more effectively than the textbook.

16. I would recommend the case-based seminar discussions as a tool for other courses.

17. I was nervous at the beginning of the term but became more confident to participate as the term progressed.
4

+/- 1.0

4.4

+/- 0.8

4.4

+/- 0.8

4.1

+/- 0.9
0.679

0.409

0.585

0.565

0.432

${ }^{\mathrm{a}}$ Likert scale, $1=$ Strongly disagree, $2=$ Disagree, $3=$ Neither agree or disagree, $4=$ Agree, $5=$ Strongly agree

${ }^{\mathrm{b}}$ Correlations between variables and factors after Varimax rotation

$\S$ Significantly different from all but one statement in the corresponding section

The average responses to the nine items from the survey in APP that referred to knowledge acquisition and application in pharmacology/pathophysiology ranged from 3.9 to 4.6 (Table 4, items 1-9). The statement "I feel more prepared to act as an advocate on behalf of my patient to ensure the most positive state of health possible in the presence of an illness/disease state" had an average response of 4.6; this value was significantly higher than all other responses in the corresponding category. The statement "I feel confident in my ability to prioritize diagnostic procedures required to identify an illness/disease state" had an average response of 3.9; this was significantly different from all other responses in the corresponding section except statement 7 .

Table 4

Mean survey responses plus factor analysis results for APP course

\begin{tabular}{|c|c|c|}
\hline Survey Questions & $\begin{array}{l}\text { Mean } \quad \text { F1 }^{\mathrm{b}} \\
\text { Response }^{\mathrm{a}} \\
+/- \text { sd }\end{array}$ & $\mathbf{F} 2^{\mathrm{b}}$ \\
\hline $\begin{array}{l}\text { 1. I feel confident in my ability to read a case study and } \\
\text { select the key patient factors that may impact safe and } \\
\text { effective use of medications. }\end{array}$ & $\begin{array}{l}4.3 \\
+/-0.5\end{array}$ & 0.651 \\
\hline $\begin{array}{l}\text { 2. I feel confident in my ability to understand the } \\
\text { mechanism of action of a medication based on its class. }\end{array}$ & $\begin{array}{l}4.2 \\
+/-0.5\end{array}$ & 0.543 \\
\hline $\begin{array}{l}\text { 3. I feel confident in my ability to link the therapeutic } \\
\text { benefit of a medication to its mechanism of action. }\end{array}$ & $\begin{array}{l}4.3 \\
+/-0.6\end{array}$ & 0.602 \\
\hline $\begin{array}{l}\text { 4. I feel confident in my ability to prioritize the expected } \\
\text { safety issues associated with a medication in an individual } \\
\text { patient. }\end{array}$ & $\begin{array}{l}4.1 \\
+/-0.5\end{array}$ & 0.584 \\
\hline
\end{tabular}


5. I feel confident in my ability to understand the pathophysiology of a patient's illness/disease state.

6. I feel confident in my ability to prioritize diagnostic procedures required to identify an illness/disease state.

7. I feel confident in my ability to prioritize nursing interventions for a specific illness/disease state.

8. I feel confident in my ability to read a case study and select the key patient factors that may impact the progression of an illness/disease state.

9. I feel more prepared for clinical as a result of participating in the case discussions in tutorial.
4.2

$+/-0.5$

$3.9^{\S}$

$+/-0.9$

4.1

$+/-0.8$

4.3

$+/-0.6$

$4.6^{¥}$

0.652

0.447

0.711

$+/-0.5$
10. Participation in seminars made me more confident in

4.5

$+/-0.6$ effective use of a medication.

11. Participation in seminars made me more confident to prioritize the safety issues when using a medication in an individual patient.

12. Participation in seminars made me more confident to prioritize the nursing interventions associated with a variety of critical illnesses.

13. Participation in seminars made me feel more prepared to advocate for my patient.

14. The cases were relevant and interesting.

15. I would recommend the flipped classroom format (no lectures, seminars only with assigned readings) as a tool for other courses.

16. I was nervous at the beginning of the term but became more confident to participate as the term progressed.
4.4

$+/-0.6$

4.3

$+/-0.6$

4.1

$+/-0.6$

$4.7^{¥}$

$+/-0.5$

$3.8^{¥}$

$+/-0.9$

4.2 0.542

$+/-0.9$

${ }^{\mathrm{a}}$ Likert scale, $1=$ strongly disagree, $2=$ disagree, $3=$ neither agree or disagree, $4=$ agree, $5=$ strongly agree

${ }^{\mathrm{b}}$ Correlations between variables and factors after Varimax rotation

¥ Significantly different from all statements in the corresponding section

$\S$ Significantly different from all but one statement in the corresponding section

\section{Case studies as a learning model in pharmacology/pathophysiology}

The average responses for the six items from the survey in PHARM that referred to the case study as a learning model ranged from 3.8 to 4.3 (Table 2, items 11-16). The statement "I found the seminars assisted my learning more effectively than lectures" had an average response 
of 3.8; this value was lower than all other responses in the section. None of the remaining statements were consistently different from other statements in this section.

The average responses for the eight items from the survey in PATHO that referred to the case study as a learning model ranged from 4 to 4.4 (Table 3, items 10-17). None of the average responses were different from the other responses in this section.

The average responses to the seven items from the survey in APP that referred to the case study as a learning model ranged from 3.8 to 4.7 (Table 4, questions 10-16). The statement "The cases were relevant and interesting" has a response mean of 4.7 ; this value was significantly higher than all other responses in the corresponding category. The statement "I would recommend the flipped classroom format (no lectures, seminars only with assigned readings) as a tool for other courses" has a response mean of 3.8; this value was significantly lower than all other responses in the corresponding category.

\section{Factor Analysis Results}

Data from each course was analyzed separately (Tables 2 and 3). In each analysis, the Kaiser-Meyer-Olkin measure (KMO) was 0.80 , indicating the suitability of this data for EFA. When factor analysis of the data was performed, the presence of two factors was detected for each course. In each analysis, the two factors accounted for approximately $40 \%$ of the variance. A cut-off value of 0.4 was used for factor loading. For simplicity, only values that exceeded 0.4 were shown on the tables (Tables 2 and 3).

The statements loaded onto the factors in the same fashion for each course. The two factors corresponded to the two sections of each survey. For PHARM, the Cronbach alpha for Factor 1 was 0.845 and for Factor 2 was 0.801. For PATHO, the Cronbach alpha for Factor 1 was 0.850 and for Factor 2 was 0.808 . For APP, the Cronbach alpha for Factor 1 was 0.840 and for Factor 2 was 0.826.

When examining the statements associated with Factor 1 to name this factor, it was noted that "my ability to analyze" and "my ability to prioritize" were loaded highly in both courses. Therefore, Factor 1 was designated "self-efficacy and critical reasoning with pharmacology and pathophysiology in patient care." This scale can be used as a measure of perceived self-efficacy. When examining the statements associated with Factor 2, "confident in analyzing" and "recommendation as a tool" were loaded highly in both courses. Therefore Factor 2 was designated as "confidence in the learning model" to link these concepts. This scale can be used as a measure of student satisfaction as to how well a learning model supports their learning.

\section{Discussion}

Nursing students are required to learn significant amounts of complex content in pharmacology and pathophysiology. Effective teaching and learning strategies in pharmacology and pathophysiology that include situated and active learning may help to develop critical thinking in nursing students to help to ensure medication safety in complex patient care situations (Benner et al., 2010; Chan, 2013; Forsgren et al., 2014). The flipped classroom, which can provide this rich learning environment, is often used in nursing education (Bergmann \& Sams, 2012; Chan, 2013; Hanson, 2016; Missildine et al., 2013; Peisachovich et al., 2016; Schlairet et al., 2014; Schwartz, 2014). While the flipped classroom has been shown to improve midterm test performance in pharmacology (Geist et al., 2015), it is not clear from these studies which specific learning strategies are being employed to flip the classroom in nursing education. 
Case studies are commonly used as an active learning strategy in a flipped classroom (Bergmann \& Sams, 2012; Wood, 2003). Case studies have been shown to enhance nursing students' ability to look at patient data and make more thoughtful clinical decisions (Bertacchini et al., 2016; Forsgren et al., 2014; Kantar \& Massouh, 2015). Case study discussions that take place in small groups have the potential for interactive guidance of learning by an instructor. This small group active learning situation is more beneficial than traditional lectures for nursing student learning and enhances critical thinking in nursing students (Bailey, 2017; Bertacchini et al., 2016; Carvalho et al., 2017; Chan, 2013; Kalaian \& Kasim, 2017; Kong, Qin, Zhou, Mou, \& Gao, 2014; Lee et al., 2017). Higher-level thinking and independent learning are improved with the use of small and interactive groups (Alton, 2016; Gholami et al., 2016). A limited number of studies have examined the use of case studies in nursing (Bailey, 2017; Forsgren et al., 2014); more in-depth assessment of the case study and other learning tools is required to establish best practices in nursing education (Betihavas et al., 2016; Njie-Carr et al., 2017). The development of a tool to assess case studies and other learning models for their impact on the learning of nursing students may be useful.

Irrespective of course content, nursing students in this study perceived that case studies were a useful model to enhance their learning. Higher confidence was expressed in pharmacology knowledge acquisition and application around the mechanism of action, therapeutic benefit, adverse effects, and contraindications of a medication than in learning around potential drug/food/herbal interactions (Table 2). Higher confidence was expressed in pathophysiology knowledge acquisition and application around the signs and symptoms, risk factors and general pathophysiology of an illness than around etiology, prognosis and diagnostic tests associated with an illness (Table 3). Confidence in knowledge acquisition and application was high in all aspects of pharmacology and most aspects of pathophysiology in the combined APP course; lower confidence was apparent around content in diagnostic tests (Table 4).

Participation in case studies was viewed as a positive learning strategy, irrespective of the course content. While case studies were not examined specifically, a belief that the flipped classroom effectively supported the learning of pharmacology content has been demonstrated (Hanson, 2016). In both the PHARM and APP courses, a lower response was present when students were asked to reflect on whether case studies assisted their learning more effectively than lectures. The response was not negative, it was simply less positive than the responses to other statements. This may reflect the discomfort that sometimes exists when students are unsure of the content and would be happier with a lecture because they feel more assured that a lecture format will make clear exactly what they are expected to know (Benner et al., 2010), especially if the lecturer is engaging and organized. This finding confirms that student satisfaction may not always accurately reflect student learning (Benner et al., 2010; Bergmann \& Sams, 2012). This was not present in the evaluation from the PATHO course. This is supported by an increased satisfaction with learning seen when case studies were implemented in a second-year pathophysiology course in Portugal (Oliveira Marques, \& Maia Correia, 2017).

The consistency of the factor analysis data across all courses suggests that the items and corresponding scales created in this study are reliable and can be used as a scale to assess perceptions of learning and satisfaction with a learning model. The case study format is recommended by all three groups of students, corroborating the use of this scale to assess attitudes towards a learning model. The scale used to assess the development of self-efficacy has suggested potential content concerns in each course. Future study may be helpful to understand 
this potential issue. The scales developed in this study can be applied to assess other learning tools in pharmacology and pathophysiology.

\section{Conclusion}

Case studies in small groups are an effective learning model to enhance critical thinking in nursing students. This model was found to be perceived by nursing students to develop their self-efficacy as they apply their knowledge of pathophysiology and pharmacology in assessing key patient risks while providing patient care. The case study model is perceived by students to be a useful learning strategy tool to support the learning of pathophysiology and pharmacology content. A tool was developed to assess student perceptions of a learning strategy and to measure self-efficacy related to the application of knowledge in the life sciences to patient care.

\section{Implications}

This tool reflects perceived knowledge acquisition by students and not the actual acquisition of knowledge. This tool could be used in future studies along with an assessment of knowledge acquisition to provide further evidence of the potential strengths of case studies as a learning model. This tool can also be used to compare different learning strategies (e.g., games, drug-card design, and practice problems) to determine best practices around active learning strategies that support learning in a flipped classroom in nursing education.

\section{Limitations}

This tool was only developed and studied in life science courses in nursing at the secondand third-year levels. These courses tend to be similar in approach and content, with a heavy reliance on fact acquisition and application of knowledge. Therefore, the tool may not be applicable to nursing theory courses, which are more concept-based, or to different levels of student. No adjustment was made for previous experience that students may have had with the case study model or for previous experience as a health care worker. 


\section{References}

Al-Kloub, M. I., Salameh, T. N., \& Froelicher, E. S. (2014). Nursing students evaluation of problem based learning and the impact of culture on the learning process and outcomes: A pilot project. Nurse Education in Practice, 14(2), 142-147. https://doi.org/10.1016/j.nepr.2013.06.013

Alexandre, M. S., \& Wright, R. R. (2013). Flipping the Classroom for Student Engagement. International Journal of Nursing Care, 1(2), 100-104. http://doi.org/10.5958/j.2320$\underline{8651.1 .2 .043}$

Alton, S. (2016). Learning how to learn: Meta-learning strategies for the challenges of learning pharmacology. Nurse Education Today, 38, 2-4. https://doi.org/10.1016/j.nedt.2016.01.003

Armitage, G. R., \& Knapman, H. (2003). Adverse events in drug administration: a literature review. Journal of Nursing Management, 11, 130-140. https://doi.org/10.1046/j.13652834.2003.00359.x

Arrue, M., Ruiz de Alegría, B., Zarandona, J., \& Hoyos Cillero, I. (2017). Effect of a PBL teaching method on learning about nursing care for patients with depression. Nurse Education Today, 52, 109-115. https://doi.org/10.1016/j.nedt.2017.02.016

Atherton, H. (2015). Problem-based learning in pre-registration mental health nursing: the student experience. Mental Health Practice, 19(1), 28-33. https://doi.org/10.7748/mhp.19.1.28.e1005

Bailey, L. A. (2017). Adaptation of Know, Want to Know, and Learned Chart for Problem-Based Learning. Journal of Nursing Education, 56(8), 506-508. https://doi.org/10.3928/01484834-20170712-11

Bandura, A. (2006). "Guide to creating a self-efficacy scale.” In F. Pajares \& T. Urdan (Eds.) Self-efficacy Beliefs of Adolescents (pp. 307-337). Charlotte, NC: Information Age Publishing.

Benner, P., Sutphen, M., Leonard, V., \& Day, L. (2010). Educating nurses: A call for radical transformation. San Francisco, CA: Jossey-Bass.

Bergmann, J., \& Sams, A. (2012). Flip Your Classroom: Reach Every Student in Every Class Every Day. Eugene, OR: International Society for Technology in Education.

Bertacchini de Oliveira, L., Rueda Díaz, L. J., da Costa Carbogim, F., Baldacin Rodrigues, A. R., $\&$ de Araújo Püschel, V. A. (2016). Effectiveness of teaching strategies on the development of critical thinking in undergraduate nursing students: a meta-analysis. Revista Da Escola de Enfermagem Da USP, 50(2), 350-359. https://doi.org/10.1590/S0080-623420160000200023

Betihavas, V., Bridgman, H., Kornhaber, R., \& Cross, M. (2016). The evidence for "flipping out": A systematic review of the flipped classroom in nursing education. Nurse Education Today, 38, 15-21. http://doi.org/10.1016/j.nedt.2015.12.010

Boggs, P., Brown-Molnar, C. S., \& DeLapp, T. D. (1988). Nurses' drug knowledge. Western Journal of Nursing Research, 10, 84-93. https://doi.org/10.1177/019394598801000108 
Brady, A., Malone, A., \& Fleming, (2009). A literature review of the individual and systems factors that contribute to medication errors in nursing practice. Journal of Nursing Management, 17(6), 679-697. https://doi.org/10.1111/j.1365-2834.2009.00995.x

Breytenbach, C., ten Ham-Baloyi, W., \& Jordan, P. J. (2017). An Integrative Literature Review of Evidence-Based Teaching Strategies for Nurse Educators. Nursing Education Perspectives, 38(4), 193-197. doi:10.1097/01.NEP.0000000000000181

Bristol, T. (2014). Educate, Excite, Engage. Teaching and Learning in Nursing, 9(1), 43-46. http://doi.org/10.1016/j.teln.2013.11.002

Carvalho, D. P. S. R. P., Azevedo, I. C., Cruz, G. K. P., Mafra, G. A. C., Rego, A. L. C., Vitor, A. F., ... Ferreira Júnior, M. A. (2017). Strategies used for the promotion of critical thinking in nursing undergraduate education: A systematic review. Nurse Education Today, 57, 103-107. https://doi.org/10.1016/j.nedt.2017.07.010

Chan, Z. C. Y. (2013) A systematic review of critical thinking in nursing education. Nurse Education Today, 33, 236-240. https://doi.org/10.1016/j.nedt.2017.07.010

Chan, Z. C. Y. (2014). Exploration of artistry in nursing teaching activities. Nurse Education Today, 34(6), 924-928. https://doi.org/10.1016/j.nedt.2013.11.009

Chiang, V. C. L., Leung, S. S. K., Chui, C. Y. Y., Leung, A. Y. M., \& Mak, Y. W. (2013). Building life-long learning capacity in undergraduate nursing freshmen within an integrative and small group learning context. Nurse Education Today, 33(10), 11841191. https://doi.org/10.1016/j.nedt.2012.05.009

Christiansen, S., Buus Bøje, R., \& Frederiksen, K. (2015). The use of problem- and simulationbased learning: The student's perspective. Nordic Journal of Nursing Research, 35(3), 186-192. https://doi.org/10.1177/0107408315591777

Forsgren, S., Christensen, T., \& Hedemalm, A. (2014). Evaluation of the case method in nursing education. Nurse Education in Practice, 14(2), 164-169. https://doi.org/10.1016/j.nepr.2013.08.003

Geist, M. J., Larimore, D., Rawiszer, H., \& Al Sager, A.W. (2015). Flipped versus traditional instruction and achievement in a baccalaureate nursing pharmacology course. Nursing Education Perspectives, 36(2), 114-115. http://dx.doi.org/10.5480/13-1292

Gholami, M., Moghadam, P. K., Mohammadipoor, F., Tarahi, M. J., Sak, M., Toulabi, T., \& Pour, A. H. H. (2016). Comparing the effects of problem-based learning and the traditional lecture method on critical thinking skills and metacognitive awareness in nursing students in a critical care nursing course. Nurse Education Today, 45, 16-21. https://doi.org/10.1016/j.nedt.2016.06.007

Hanson, J. (2016). Surveying the experiences and perceptions of undergraduate nursing students of a flipped classroom approach to increase understanding of drug science and its application to clinical practice. Nurse Education in Practice, 16, 79-85. http://dx.doi.org/10.1016/j.nepr.2015.09.001

Horn, M. (2013). The transformational potential of flipped classrooms. Education Next, 13(3), 78-79. Retrived from http://educationnext.org/files/ednext_XIII_3_whatnext.pdf 
Kalaian, S. A., \& Kasim, R. M. (2017). Effectiveness of various innovative learning methods in health science classrooms: a meta-analysis. Advances in Health Sciences Education, 22(5), 1151-1167. https://doi.org/10.1007/s10459-017-9753-6

Kantar, L. D., \& Massouh, A. (2015). Case-based learning: What traditional curricula fail to teach. Nurse Education Today, 35(8), e8-e14. https://doi.org/10.1016/j.nedt.2015.03.010

Kellar, S. P., \& Kelvin, E. A. (2012). MUNRO's Statistical methods for health care research. Philadelphia, PA: Lippincott Williams \& Wilkins.

Lee, M.-N., Nam, K.-D., \& Kim, H.-Y. (2017). Effects of simulation with problem-based learning program on metacognition, team efficacy, and learning attitude in nursing students nursing care with increased intracranial pressure patient. Computers Informatics Nursing, 35(3), 145-151. https://doi.org/10.1097/CIN.0000000000000308

Leufer, T., \& Cleary-Holdforth, J. (2013). Let's do no harm: Medication errors in nursing: Part 1. Nurse Education in Practice, 13(3), 213-216. http://doi.org/10.1016/j.nepr.2013.01.013

Kong, L.-N., Qin, B., Zhou, Y.-Q., Mou, S.-Y., \& Gao, H.-M. (2014). The effectiveness of problem-based learning on development of nursing students' critical thinking: A systematic review and meta-analysis. International Journal of Nursing Studies, 51(3), 458-469. https://doi.org/10.1016/j.ijnurstu.2013.06.009

Martyn, J., Terwijn, R., Kek, M. Y. C. A., \& Huijser, H. (2014). Exploring the relationships between teaching, approaches to learning and critical thinking in a problem-based learning foundation nursing course. Nurse Education Today, 34(5), 829-835. https://doi.org/10.1016/j.nedt.2013.04.023

Meechan, R., Mason, V., \& Catling, J. (2011). The impact of an integrated pharmacology and medicines management curriculum for undergraduate adult nursing students on the acquisition of applied drug/pharmacology knowledge. Nurse Education Today, 31(4), 383-389. http://doi.org/10.1016/j.nedt.2010.07.011

Missildine, K., Fountain, R., Summers, L., \& Gosselin, K. (2013). Flipping the classroom to improve student performance. Journal of Nursing Education, 52, 597-599. https://doi.org/10.3928/01484834-20130919-03

Morrison-Griffiths, S., Snowden, M. A., \& Pirmohamed, M. (2002). Pre-registration nurse education in pharmacology: is it adequate for the roles that nurses are expected to fulfil? Nurse Education Today, 22(6), e447-e456. https://doi.org/10.1054/nedt.2002.0756

Mrunalini, V. J. S., \& Chandekar, P. A. (2015). Perception and Opinion of Problem Based Learning (PBL) among Student Nurses. International Journal of Nursing Education, 7(3), 40-44. https://doi.org/10.5958/0974-9357.2015.00131.2

Ndosi, M. E., \& Newell, R. (2008). Nurses' knowledge of pharmacology behind drugs they commonly administer. Journal of Clinical Nursing, 18, 570-580. https://doi.org/10.1111/j.1365-2702.2008.02290.x

Njie-Carr, V. P. S., Ludeman, E., Lee, M. C., Dordunoo, D., Trocky, N. M., \& Jenkins, L. S. (2017). An integrative review of flipped classroom teaching models in nursing education. Journal of Professional Nursing, 33(2), 133-144. http://dx.doi.org/10.1016/j.profnurs.2016.07.001 
O'Brocta, R., \& Swigart, S. (2013). Student perceptions of a top 200 medication course utilizing active learning techniques. Currents in Pharmacy Teaching and Learning, 5(1), 49-53.e. https://doi.org/10.1016/j.cptl.2012.09.001

Oliveira Marques, P. A., \& Maia Correia, N. C. (2017). Nursing Education Based on "Hybrid" Problem-Based Learning: The Impact of PBL-Based Clinical Cases on a Pathophysiology Course. Journal of Nursing Education, 56(1), 60-60. https://doi.org/10.3928/01484834$\underline{20161219-12}$

Peisachovich, E. H., Murtha, S., Phillips, A., \& Messinger, G. (2016). Flipping the Classroom: A Pedagogical Approach to Applying Clinical Judgment by Engaging, Interacting, and Collaborating with Nursing Students. International Journal of Higher Education, 5(4), 114-121. https://doi.org/10.5430/ijhe.v5n4p114

Prince, M. (2004). Does active learning work? A review of the research. Journal of Engineering Education, 93, 223-231. https://doi.org/10.1002/j.2168-9830.2004.tb00809.x

Sams, A., \& Bergmann, J. (2013). Flip your students' learning. Educational Leadership, 70(6), $16-20$.

Schlairet, M. C., Green, R., \& Benton, M. J. (2014). The flipped classroom: Strategies for an undergraduate nursing course. Nurse Educator, 39, 321-325. https://doi.org/10.1097/nne.0000000000000096

Schwartz, T. A. (2014). Flipping the statistics classroom in nursing education. Journal of Nursing Education, 53, 199-206. doi:10.3928/0148434-20140325-02

Sullivan, G. M., \& Artino, A.R. (2013). Analyzing and Interpreting Data From Likert-Type Scales. Journal of Graduate Medical Education, 5(4), 541-542. http://dx.doi.org/10.4300/JGME-5-4-18

Tune, J. D., Sturek, M., \& Basile, D. P. (2013). Flipped classroom model improves graduate student performance in cardiovascular, respiratory, and renal physiology. Advances in Physiology Educcation, 37(4), 316-320. https://doi.org/10.1152/advan.00091.2013

Wood, D. F. (2003). Problem based learning. (ABC of learning and teaching in medicine). British Medical Journal, 326(7384), 328-330. https://doi.org/10.1136/bmj.326.7384.328

Yong, A. G., \& Pearce, S. (2013) A Beginner's Guide to Factor Analysis: Focusing on Exploratory Factor Analysis. Tutorials in Quantitative Methods for Psychology, 9(2), 79 94. https://doi.org/10.20982/tqmp.09.2.p079 